\title{
Macrophage gene expression is related to obesity and the metabolic syndrome in human subcutaneous fat as well as in visceral fat
}

\author{
E. Klimcakova • B. Roussel • Z. Kovacova • M. Kovacikova • M. Siklova-Vitkova • \\ M. Combes $\cdot$ J. Hejnova $\cdot$ P. Decaunes $•$ J. J. Maoret $\cdot$ T. Vedral $\cdot$ N. Viguerie • \\ V. Bourlier • A. Bouloumié • V. Stich $\cdot$ D. Langin
}

Received: 4 September 2010 / Accepted: 25 November 2010 / Published online: 26 January 2011

(C) Springer-Verlag 2011

\begin{abstract}
Aims/hypothesis Our goal was to identify a set of human adipose tissue macrophage (ATM)-specific markers and investigate whether their gene expression in subcutaneous adipose tissue (SAT) as well as in visceral adipose tissue (VAT) is related to obesity and to the occurrence of the metabolic syndrome.

Methods ATM-specific markers were identified by DNA microarray analysis of adipose tissue cell types isolated from SAT of lean and obese individuals. We then analysed gene expression of these markers by reverse transcription quantitative PCR in paired samples of SAT and VAT from 53 women stratified into four groups (lean, overweight, obese and obese with the metabolic syndrome). Anthropometric measurements, euglycaemic-hyperinsulinaemic
\end{abstract}

E. Klimcakova $\cdot$ Z. Kovacova $\cdot$ M. Kovacikova $\cdot$

M. Siklova-Vitkova $\cdot$ J. Hejnova $\cdot$ V. Stich

Franco-Czech Laboratory for Clinical Research on Obesity,

Department of Sports Medicine, 3rd Faculty of Medicine,

Charles University,

Prague, Czech Republic

B. Roussel $\cdot$ M. Combes $\cdot$ J. J. Maoret $\cdot$ N. Viguerie $\cdot$ D. Langin Franco-Czech Laboratory for Clinical Research on Obesity, Inserm, U1048, Obesity Research Laboratory,

Institute of Metabolic and Cardiovascular Diseases,

Toulouse, France

B. Roussel $\cdot$ M. Combes $\cdot$ J. J. Maoret $\cdot$ N. Viguerie $\cdot$ V. Bourlier $\cdot$

A. Bouloumié $\cdot$ D. Langin

UPS, Bio-Medical Research Federative Institute of Toulouse,

Paul Sabatier University, University of Toulouse,

IFR150, Toulouse, France

P. Decaunes $\cdot$ V. Bourlier • A. Bouloumié

Inserm, U1048, 'Stroma-Vascular Cells of Adipose Tissue' Team, Institute of Metabolic and Cardiovascular Diseases,

Toulouse, France clamp, blood analysis and computed tomography scans were performed.

Results A panel of 24 genes was selected as ATM-specific markers based on overexpression in ATM compared with other adipose tissue cell types. In SAT and VAT, gene expression of ATM markers was lowest in lean and highest in the metabolic syndrome group. mRNA levels in the two fat depots were negatively correlated with glucose disposal rate and positively associated with indices of adiposity and the metabolic syndrome.

Conclusions/interpretation In humans, expression of ATMspecific genes increases with the degree of adiposity and correlates with markers of insulin resistance and the metabolic syndrome to a similar degree in SAT and in VAT.

T. Vedral

Department of Surgery, University Hospital Kralovské Vinohrady, Prague, Czech Republic

D. Langin

Biochemistry Laboratory, Biology Institute of Purpan, CHU de Toulouse,

Toulouse, France

Present Address:

E. Klimcakova $(\square)$

The Rosalind and Morris Goodman Cancer Research Centre, McGill University,

McIntyre Medical Sciences Building, Room 713, 3655

Promenade Sir William Osler,

Montreal, QC, Canada H3G 1Y6

e-mail: eva.klimcakova@mcgill.ca 
Keywords Human adipose tissue - Inflammation . Macrophage $\cdot$ Metabolic syndrome $\cdot$ Obesity $\cdot$ Subcutaneous fat $\cdot$ Visceral fat

\section{Abbreviations \\ ATM Adipose tissue macrophage \\ SAT Subcutaneous adipose tissue \\ SVF Stromavascular fraction \\ VAT Visceral adipose tissue}

\section{Introduction}

In obesity, adipose tissue generates a local and systemic low-grade inflammatory environment. The first reports linking inflammation and carbohydrate metabolism date back to the 1800 s and the clinical evidence of an association between inflammation and obesity to the 1950s [1]. Adipose tissue inflammation attracted increased attention after the key discoveries of a role for TNF $\alpha$ in obesity-linked insulin resistance in 1993 and of macrophage infiltration into adipose tissue in 2003 [2]. Since then, intense research on the factors initiating adipose tissue inflammation and promoting obesity-related metabolic abnormalities such as type 2 diabetes has been ongoing, but the problem remains imperfectly understood especially in humans. The term the metabolic syndrome was introduced to denote a cluster of metabolic disorders with an atherogenic, prothrombotic and inflammatory profile [3, 4]. The key components of the metabolic syndrome are insulin resistance and abdominal adiposity, with a predominance of intra-abdominal visceral fat accumulation [5].

The pathogenic potential of adipose tissue seems to be determined, besides total adiposity as such, by specific anatomic location $[3,6]$ or phenotypic and functional differences between subcutaneous adipose tissue (SAT) and visceral adipose tissue (VAT). Indeed, although abdominal SAT and VAT are associated with metabolic risk profile [7], it has previously been reported [7-9] and recently confirmed in the Framingham Heart Study [10] that high VAT has a stronger correlation with metabolic risk factors and the metabolic syndrome than SAT. Several studies report depot-specific differences in inflammatory function based on higher number of macrophages [11-13], macrophage crown-like structures [14] and/or elevated levels of inflammatory molecules in VAT compared with SAT of obese individuals $[11,15-17]$.

The potential factors disturbing adipose tissue function in obesity are numerous. In expanding human adipose tissue, fat cell hypertrophy [18], altered production of adipokines, and increased number of macrophages [11-13] and lymphocytes [19] are considered to be major 'stressors'. Macrophages populate all tissues as quiescent but vital homeostatic cell populations with a primary role in clearing cellular debris [20,21]. Macrophages differentiate from blood monocytes, which migrate into tissue in the steady state or in response to different stimuli that initialise macrophage activation. Depending on the type of stimuli, activated macrophages change phenotype and immune function in order to adapt to the local microenvironment. Interestingly, environmental signals do not necessarily increase macrophage immune function (secretion of pro- and anti-inflammatory cytokines), but can give rise to macrophages that are less equipped to produce cytokines [21]. Macrophage classification based on the two extreme states of polarisation ('classically activated' M1, 'alternatively activated' M2) has recently been discussed and new, more objective classification encompassing three basic macrophage populations has been proposed with anticipation that it may be further expanded [21]. Accordingly, recent data suggest that human adipose tissue macrophages (ATM) show a complex phenotype and are not strictly polarised into M1 and M2 [22, 23]. Several studies have examined expression levels of a few ATM genes in different groups of individuals [12, 13, 16, 24-26]. Given the interplay of biological systems, it is evident that reliance on a single or a few markers should be replaced by a spectrum of specific markers for study of ATM [1].

The present study was designed to investigate expression of specific human ATM genes in SAT and in VAT. We hypothesised that ATM gene expression may increase with adiposity and be related to the presence of the metabolic syndrome. We identified a panel of new human ATM-specific markers and determined mRNA levels in SAT and VAT of well-characterised groups of lean, overweight and obese individuals without and with the metabolic syndrome. The gene expression profile of ATM markers in both fat depots was correlated with indices of adiposity, variables of the metabolic syndrome, direct measurement of insulin sensitivity and computer tomography-derived measures of abdominal SAT and VAT compartments.

\section{Methods}

Identification of human adipose tissue cell type-specific genes Adipocytes and stromavascular fraction (SVF) were isolated from liposuction-obtained abdominal SAT of six women (BMI $24 \pm 1 \mathrm{~kg} / \mathrm{m}^{2}$, age $36 \pm 4$ years [means $\pm \mathrm{SD}$ ]) by collagenase digestion. Macrophages, endothelial cells, progenitor cells and a negative fraction containing lymphocytes, mastocytes and other cells from SVF were obtained by 
immunoselection and depletion [27, 28]. First, CD34-positive cells $\left(\mathrm{CD} 34^{+}\right)$and $\mathrm{CD} 34$-negative cells $\left(\mathrm{CD} 34^{-}\right)$were isolated from the SVF by use of CD34-coupled magnetic microbeads. Then macrophages $\left(\mathrm{CD} 34^{-} / \mathrm{CD} 14^{+}\right)$were sorted from CD $34^{-}$population by immunoselection using CD14coupled magnetic microbeads. The endothelial cells $\left(\mathrm{CD} 34^{+} /\right.$ $\mathrm{CD} 31^{+}$) were sorted from $\mathrm{CD} 34^{+}$population by immunoselection using CD31-coupled magnetic microbeads. The progenitor cells were defined as $\mathrm{CD} 34^{+} / \mathrm{CD} 31^{-}$population. The negative fraction $\left(\mathrm{CD} 34^{-} / \mathrm{CD} 14^{-} / \mathrm{CD} 31^{-}\right)$was sorted from $\mathrm{CD} 34^{-} / \mathrm{CD} 14^{-}$population by depletion using $\mathrm{CD} 31$ coupled magnetic microbeads. Compared with the amount of cells from SVF, the mean yield was $3.0 \pm 0.4,4.7 \pm 0.7,8.7 \pm$ 1.2 and $4.6 \pm 0.7 \%$ for macrophages, endothelial cells, progenitor cells and negative fraction, respectively. DNA microarrays were used to measure mRNA levels in each cell fraction. Targets were generated from $500 \mathrm{ng}$ total RNA (Low RNA Input Amplification kit; Agilent Technologies, Massy, France) and hybridised to whole genome $44 \mathrm{k}$ oligonucleotide arrays (Agilent Technologies). Data acquisition and image processing were done with a scanner (GenePix 4000B; Axon Instruments, Molecular Devices, St Grégoire, France) and Feature Extraction 8.5 (Agilent Technologies). Raw data were normalised with a global Lowess procedure and filtered with R package LIMMA (Bioconductor; Fred Hutchinson Cancer Research Center, Seattle, WA, USA). Genes specific for each adipose tissue cell type were identified with Significance Analysis of Microarray (Stanford University, Stanford, CA, USA) with an estimated false discovery rate of $5 \%$. Principal component analysis was then used to optimise selection of ATM-specific genes with highly related SAT and VAT mRNA expression profiles in the 53 women enrolled in this study (see below). To validate the selection of ATM markers, a second series of DNA microarrays was performed on abdominal SAT cell fractions from six lean (BMI 24 \pm $1 \mathrm{~kg} / \mathrm{m}^{2}$, age $36 \pm 4$ years [means $\pm \mathrm{SD}$ ]) and six obese (BMI $36 \pm 6 \mathrm{~kg} / \mathrm{m}^{2}$, age $39 \pm 7$ years [means $\pm \mathrm{SD}$ ]) individuals. This series was scanned with Innoscan 700 (Innopsys, Carbonne, France) and analysed using Mapix (Innopsys). Gene expression of the markers was analysed by hierarchical clustering (uncentred Pearson's correlation, average linkage).

Participants Individuals scheduled to have abdominal surgery (laparoscopic or laparotomic cholecystectomy, hysterectomy and gastric banding) at the Departments of Surgery and Gynecology at Kralovske Vinohrady Faculty Hospital in Prague were monitored and 53 women (age 2166 years, BMI $17.3-48.5 \mathrm{~kg} / \mathrm{m}^{2}$ ) were included. Exclusion criteria were: malignancy, current inflammatory conditions as diagnosed by clinical status and laboratory findings, known endocrinopathy, chronic liver or kidney disease, psychiatric disorders and body weight fluctuations $>2 \%$ over the preceding 3 months. Each participant gave written informed consent and the study was approved by the Ethic Committee of the Third Faculty of Medicine, Charles University, Prague. According to BMI, and presence or absence of the metabolic syndrome evaluated according to the International Diabetes Federation criteria [29], the participants were stratified into four groups: lean $(n=12)$, overweight $(n=12)$, obese $(n=15)$ and obese with the metabolic syndrome $(n=14)$.

Study protocol A clinical investigation was performed 7 14 days prior to the surgery. Anthropometric measurements, blood sampling and euglycaemic-hyperinsulinaemic clamp were performed at rest after an overnight fast. Body composition was evaluated using bioelectrical impedance (QuadScan 4000; Bodystat, Douglas, Isle of Man). Visceral and subcutaneous fat areas were derived from computed tomography scans at the level L4 to L5 [30]. Blood samples were obtained before the clamp and plasma variables were measured using standard procedures. Insulin sensitivity was assessed using euglycaemic-hyperinsulinaemic clamp [31]. During the surgical procedure, paired samples of abdominal SAT and omental VAT were obtained and processed immediately. Adipose tissue was washed in physiological saline, homogenised in RLT lysis buffer (Qiagen, Courtaboeuf, France) and stored at $-80^{\circ} \mathrm{C}$ until analysed.

RNA analysis Total RNA isolation was performed as previously described [32]. The mRNA expression of macrophage-specific genes was assessed by reverse transcription and real-time quantitative PCR using a sequence detection system (ABI PRISM 7900; Applied Biosystems, Foster City, CA, USA) and custom TaqMan low-density arrays and TaqMan gene expression assay pre-loaded targets (both from Applied Biosystems). Ribosomal 18S RNA was used as endogenous control.

Statistical analyses Clinical variables of the participants were first analysed by partial least square-discriminant analysis using SIMCA-P+ software (Umetrics/SIGMA PLUS, Siège social: 3, Toulouse, France). Partial least square-discriminant analysis is a principal component analysis-derived method used to optimise separations between groups of individuals [33]. Four groups of individuals were identified (lean, overweight, obese and the metabolic syndrome), thus confirming the initial stratification of participants according to BMI and the metabolic syndrome status. To compare clinical variables between the groups of individuals, log-transformed data were analysed by one-way ANOVA (four groups of individuals) with Bonferroni post hoc analysis using SPSS 17.0 statistical software (SPSS, Chicago, IL, USA). Gene expression analyses were done on log-transformed data using SPSS 17.0 software. Relative mRNA amounts were 
expressed as $2^{\Delta \mathrm{C}_{\mathrm{t}}}$ values, where $\Delta \mathrm{C}_{\mathrm{t}}=\mathrm{C}_{\mathrm{t}}$ (endogenous control) $-C_{t}$ (target gene). Two mean centroids \pm SEM, one for SAT and one for VAT depot, were calculated from $2^{\Delta \mathrm{C}_{\mathrm{t}}}$ mRNA values after normalisation of gene expression levels to a mean of 0 and a variance of 1 across all individuals [34]. The mean centroid is a variable that represents weighted average of the 24 gene expression levels. The mean centroids were used to compare ATM marker gene expression between the groups and, also, to assess the correlations between the genes and physiological variables. Linear mixed-effect models for repeated measures were chosen as the most appropriate analysis for the comparison of macrophage marker expression represented as mean centroids between the groups of participants (between-group factor) and between adipose tissue depots (repeated measure). All models were assessed graphically for normality of the residuals and homogeneity of variances and covariances. As the homogeneity of variance and covariance was not respected, the heterogeneous Toeplitz covariance matrix was chosen for its low Akaike's information criterion compared with different covariance structures. Bonferroni adjustment was used for multiple comparisons. The results were considered statistically significant when the two-sided $p$ value was $p<0.05$. Correlation analyses of gene expression between the two fat depots and vs clinical variables were performed using Pearson's test. To determine in which adipose tissue depot the genes were preferentially expressed, a comparison of $2^{\Delta \mathrm{C}_{\mathrm{t}}}$ values of each gene between SAT and VAT was realised by pair-wise analysis (Wilcoxon's signed rank test) for each group of participants.

\section{Results}

Human ATM-specific markers Comparison of DNA microarray gene expression data from different human adipose tissue cell types by Significance Analysis of Microarray biclass and pair-wise analyses revealed 332 ATM markers. To select highly specific ATM genes, the list was reduced according to the following criteria: (1) gene expression more than tenfold and twofold higher in macrophages than in adipocytes and other non-adipocyte cell types, respectively (DNA microarrays, data not shown); (2) more than 1.5-fold higher expression in macrophages than in SVF (DNA microarrays, data not shown); and (3) high inter-correlations of SAT and VAT gene expression in the 53 participants as tested by principal component analysis. A final list of 24 ATM-specific markers was obtained (Table 1). The selection of 24 ATM markers was validated by DNA microarray analyses on SAT of independent groups of lean and obese individuals. Hierarchical clus- tering clearly shows that the 24 genes discriminate ATM from other cell types in lean and obese individuals (Fig. 1).

Clinical variables of participants Anthropometric and metabolic characteristics of the four groups of participants are shown in Table 2. In the metabolic syndrome group, seven individuals had previously diagnosed type 2 diabetes. Body weight, fat mass, waist, WHR and insulin concentrations were lower in the lean than in the three other groups. The relative amount of visceral fat was significantly different between lean and the metabolic syndrome individuals, with higher amounts in the metabolic syndrome group. Glucose disposal rate corrected for body weight or for fat-free mass was lower in the metabolic syndrome than in lean and overweight patients. Glucose disposal rate related to body weight was decreased in obese when compared with the lean group.

Partial least square-discriminant analysis of clinical data shows distribution of 53 participants into four groups: lean, overweight, obese and the metabolic syndrome (Fig. 2). Most of the data variance was explained by two principal components. Component 1 ( $x$-axis) discriminated individuals according to degree of obesity, i.e. lean, overweight, obese. Component 2 ( $y$-axis) separated the two groups of obese individuals according to presence or absence of the metabolic syndrome. Five variables (WHR, insulin, triacylglycerol and computed tomography visceral/total fat) were the most important variables for discrimination of the metabolic syndrome group.

ATM marker mRNA expression in SAT and VAT of lean, overweight, obese and the metabolic syndrome individuals ATM marker mRNA levels, expressed as SAT and VAT mean centroids, were analysed in relation to the four groups of individuals. The expression of SAT and VAT mean centroids was lower in lean $(p<0.05)$ and higher in the metabolic syndrome $(p<0.05)$ than in the other three groups (Fig. 3). The rank order of gene expression was: lean $<$ overweight $=$ obese $<$ the metabolic syndrome. We then determined the relation between ATM marker gene expression and clinical data in the entire group of 53 participants. Associations with clinical variables are shown in Table 3. In both adipose tissue depots, centroids of ATM genes were positively correlated with BMI, weight, fat mass, waist, WHR and computed tomography visceral/total fat, and negatively correlated with fat-free mass. Positive correlations between mean centroids of ATM marker mRNA levels and plasma levels of insulin, NEFA, triacylglycerol, and systolic and diastolic blood pressure levels were observed in the two fat depots. Next, the relation between ATM marker gene expression and insulin sensitivity was investigated. Pearson's correlation analysis revealed a 
Table 1 List of 24 macrophage-specific markers derived from DNA microarray analysis of human adipose tissue cell types

Gene

\begin{tabular}{|c|c|}
\hline Official symbol & Other aliases \\
\hline$A C P 5$ & $M G C 117378, T R A P$ \\
\hline \multicolumn{2}{|l|}{$C D 14$} \\
\hline$C D 163$ & M130, MM130 \\
\hline$C D 209$ & $\begin{array}{l}\text { CDSIGN, CLEC4L, DC-SIGN, } \\
\text { DC-SIGN1, MGC129965 }\end{array}$ \\
\hline$C D 33$ & $\begin{array}{l}\text { FLJ00391, SIGLEC-3, } \\
\text { SIGLEC3, p67 }\end{array}$ \\
\hline CD68 & $\begin{array}{l}\text { DKFZp686M18236, GP110, } \\
\text { SCARD1 }\end{array}$ \\
\hline$A D A P 2$ & $\begin{array}{l}\text { CENTA2, HSA272195, } \\
\text { CENT-B }\end{array}$ \\
\hline CLEC10A & $\begin{array}{l}\text { CD301, CLECSF13, CLECSF14, } \\
H M L, H M L 2, M G L\end{array}$ \\
\hline$F C G R 2 B$ & $\begin{array}{l}\text { RP11-474I16.2, CD32, CD32B, } \\
\quad F C G 2, F C G R 2, I G F R 2\end{array}$ \\
\hline FCN1 & RP11-447M12.1, FCNM \\
\hline$H L A-D M A$ & $\begin{array}{r}D A A P-27 A 1.5, D 6 S 222 E \\
D M A, H L A D M, R I N G 6\end{array}$ \\
\hline$H L A-D R A$ & $\begin{array}{l}\text { DASS-397D15.1, FLJ51114, } \\
\text { HLA-DRA1, MLRW }\end{array}$ \\
\hline IL10 & $\begin{array}{l}\text { RP11-262N9.1, CSIF, IL-10, } \\
\quad \text { IL10A, MGC126450, } \\
\text { MGC126451, TGIF }\end{array}$ \\
\hline IRF5 & SLEB10 \\
\hline
\end{tabular}

\begin{tabular}{|c|c|}
\hline$K Y N U$ & \\
\hline$L I P A$ & RP11-341B24.1, CESD, LAL \\
\hline MARCO & AI323439, Ly112, Scara2 \\
\hline$M S 4 A 4 A$ & $\begin{array}{l}\text { HDCME31P, 4SPAN1, } \\
\text { CD20-L1, CD20L1, MGC22311, } \\
\text { MS4A4, MS4A7 }\end{array}$ \\
\hline$M S 4 A 6 A$ & $\begin{array}{l}\text { CDA01, 4SPAN3, 4SPAN3.2, } \\
\text { CD20L3, MGC131944, } \\
\text { MGC22650, MS4A6, } \\
\text { MST090, MSTP090 }\end{array}$ \\
\hline$M S 4 A 7$ & $\begin{array}{l}\text { 4SPAN2, CD20L4, CFFM4, } \\
\text { MGC22368, MS4A8 }\end{array}$ \\
\hline MSRI & $\begin{array}{l}\text { CD204, SCARA1, SR-A, } \\
\text { phSR1, phSR2 }\end{array}$ \\
\hline SIGLEC1 & $\begin{array}{l}\text { CD169, DKFZp667F058, } \\
\text { FLJ00051, FLJ00055, } \\
\text { FLJ00073, FLJ00411, } \\
\text { FLJ32150, SIGLEC-1, } \\
\text { SN, dJ1009E24.1 }\end{array}$ \\
\hline SLCO2B1 & $\begin{array}{l}\text { DKFZp686E0517, KIAA0880, } \\
\text { OATP-B, OATP } 2 B 1, \text { OATPB, } \\
\text { SLC21A9 }\end{array}$ \\
\hline TLR7 & $U N Q 248 / P R O 285$ \\
\hline
\end{tabular}

Ratio of gene expression

(macrophage : cell type listed)

\begin{tabular}{|c|c|c|c|c|c|}
\hline Official name & Adipocyte & $\mathrm{EC}$ & $\mathrm{PC}$ & $\mathrm{NF}$ & SVF \\
\hline $\begin{array}{l}\text { Acid phosphatase } 5 \\
\text { tartrate resistant }\end{array}$ & 88.9 & 4.0 & 5.1 & 2.8 & 1.7 \\
\hline CD14 molecule & 17.8 & 2.5 & 3.6 & 17.6 & 1.8 \\
\hline CD163 molecule & 120.9 & 2.5 & 4.5 & 20.1 & 1.5 \\
\hline CD209 molecule & 25.3 & 2.1 & 2.8 & 9.7 & 1.6 \\
\hline CD33 molecule & 28.5 & 4.1 & 6.6 & 2.1 & 2.8 \\
\hline CD68 molecule & 19.3 & 2.9 & 3.0 & 3.0 & 1.8 \\
\hline $\begin{array}{l}\text { ArfGAP with dual } \\
\text { PH domains } 2\end{array}$ & 61.6 & 2.8 & 4.4 & 7.4 & 1.7 \\
\hline $\begin{array}{l}\text { C-type lectin domain } \\
\text { family } 10, \text { member A }\end{array}$ & 224.4 & 6.8 & 11.6 & 8.0 & 3.2 \\
\hline $\begin{array}{l}\text { Fc fragment of } \operatorname{IgG} \text {, low } \\
\text { affinity } \mathrm{IIb} \text {, receptor }(\mathrm{CD} 32)\end{array}$ & 169.3 & 3.7 & 6.3 & 14.3 & 2.4 \\
\hline $\begin{array}{l}\text { Ficolin (collagen/fibrinogen } \\
\text { domain containing) } 1\end{array}$ & 134.8 & 11.0 & 41.7 & 12.2 & 2.9 \\
\hline $\begin{array}{l}\text { Major histocompatibility } \\
\text { complex, class II, DM alpha }\end{array}$ & 14.5 & 3.1 & 7.1 & 5.1 & 2.3 \\
\hline $\begin{array}{l}\text { Major histocompatibility } \\
\text { complex, class II, DR alpha }\end{array}$ & 45.6 & 2.8 & 6.6 & 4.0 & 2.0 \\
\hline Interleukin 10 & 27.0 & 4.3 & 9.0 & 9.9 & 2.5 \\
\hline Interferon regulatory factor 5 & 32.5 & 4.2 & 6.6 & 3.0 & 2.2 \\
\hline Kynureninase & 50.5 & 6.6 & 10.6 & 6.3 & 4.1 \\
\hline $\begin{array}{l}\text { Lipase A, lysosomal acid, } \\
\text { cholesterol esterase }\end{array}$ & 17.9 & 4.2 & 4.7 & 2.7 & 1.7 \\
\hline $\begin{array}{l}\text { Macrophage receptor with } \\
\text { collagenous structure }\end{array}$ & 36.3 & 2.5 & 4.1 & 15.3 & 1.6 \\
\hline $\begin{array}{l}\text { Membrane-spanning } \\
\text { 4-domains, subfamily A, } \\
\text { member } 4\end{array}$ & 86.1 & 2.6 & 4.4 & 7.3 & 1.8 \\
\hline $\begin{array}{l}\text { Membrane-spanning } \\
\text { 4-domains, subfamily A, } \\
\text { member 6A }\end{array}$ & 76.4 & 4.2 & 7.9 & 15.5 & 2.7 \\
\hline $\begin{array}{l}\text { Membrane-spanning 4-domains, } \\
\text { subfamily A, member } 7\end{array}$ & 15.0 & 3.0 & 5.3 & 14.3 & 5.6 \\
\hline Macrophage scavenger receptor 1 & 68.1 & 3.5 & 4.6 & 6.2 & 1.9 \\
\hline $\begin{array}{l}\text { Sialic acid binding Ig-like } \\
\text { lectin } 1 \text {, sialoadhesin }\end{array}$ & 12.8 & 3.0 & 3.6 & 3.3 & 1.8 \\
\hline $\begin{array}{l}\text { Solute carrier organic anion } \\
\text { transporter family, member } \\
\text { 2B1 }\end{array}$ & 45.0 & 2.5 & 5.7 & 3.5 & 1.5 \\
\hline Toll-like receptor 7 & 33.3 & 2.7 & 4.9 & 12.4 & 1.8 \\
\hline
\end{tabular}

Gene symbols as listed in Entrez Gene (www.ncbi.nlm.nih.gov/entrez/query.fcgi?CMD $=$ search\&DB=gene)

EC, endothelial cells; PC, progenitor cells; NF, negative fraction 


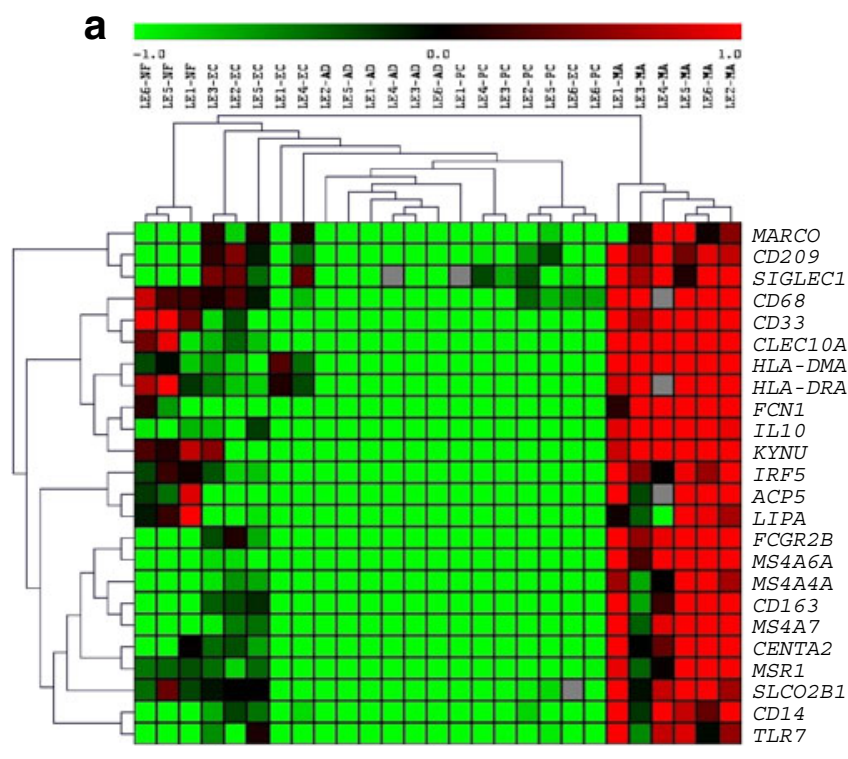

Fig. 1 Hierarchical clustering of 24 ATM marker genes expression in different human SAT cell types of lean (LE) (a) and obese (OB) (b) individuals. The ratio of the abundance of the transcripts of each gene in each cell type to a common reference pool is represented by the colour of the corresponding cell in the matrix file. Green, transcripts with lower expression than in reference pool; red, transcripts with

negative correlation when mean centroids of ATM markers in VAT and SAT were related to glucose disposal rate corrected for fat-free mass (Fig. 4a, b, Table 3) or glucose disposal rate related to body weight (Table 3 ).

Comparison of ATM marker mRNA expression in subcutaneous vs visceral fat depot Significant positive correlation was found between mean centroids of ATM-specific genes in SAT and VAT (Fig. 5). For each individual's group, a pair-wise analysis was realised to compare the expression of each macrophage-specific gene between VAT and SAT depot. The results are presented in Table 4. There was no significant difference between SAT and VAT in expression of CD14, M130 (also known as CD163), CD301 (also known as CLEC10A), FCNM (also known as FCN1) and $H L A D M$ (also known as HLA-DMA) in any of the individuals' groups. For the other genes, two noticeable patterns were observed: (1) in lean individuals, ten genes showed higher expression in VAT, while their expression was generally not different in other groups (except for three instances); (2) in overweight, obese or the metabolic syndrome individuals, four to ten genes showed higher expression in SAT, while their expression was generally not different in the lean group (except for two instances). TRAP (also known as $A C P 5$ ) expression showed a clear difference between lean individuals and the other three groups, i.e. it was higher in VAT in lean individuals, while it was significantly higher in SAT in the overweight, obese and obese metabolic syndrome groups.

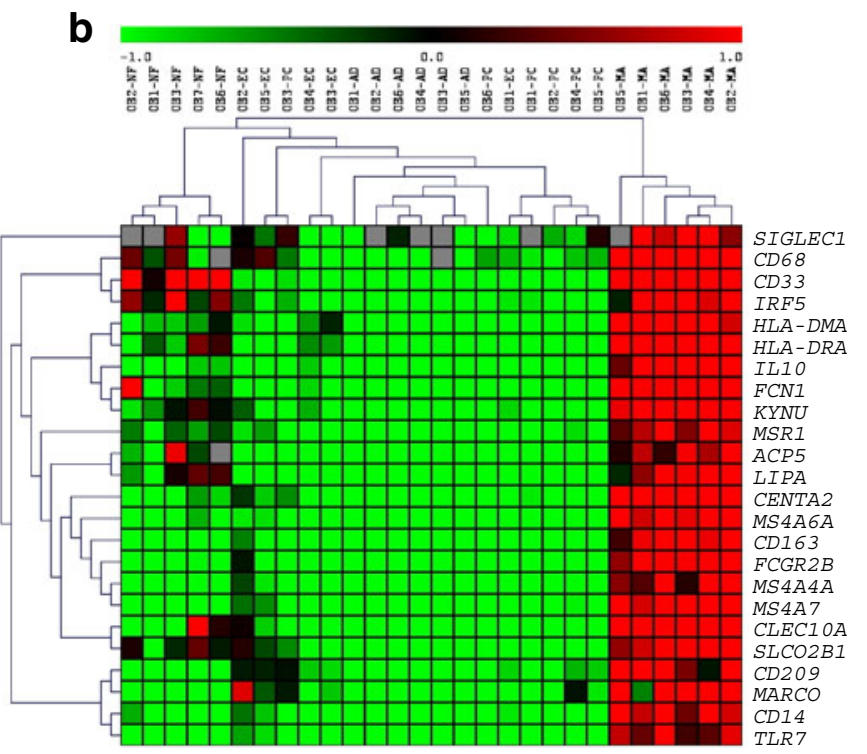

higher expression than in reference pool. Horizontal dendograms, similarities in expression pattern between adipose tissue cell types in LE and OB individuals; vertical dendrograms, clustering of genes. $\mathrm{AD}$, adipocytes; $\mathrm{EC}$, endothelial cells; PC, progenitor cells; NF, negative fraction; MA, macrophages. For gene names, see Table 1

\section{Discussion}

In the present study, we used non-hypothesis-driven DNA microarray technology to identify 24 human ATM-specific markers by comparison of gene expression profiles in various adipose tissue cell types. We also investigated whether gene expression levels of these markers in abdominal SAT and VAT differ in obesity and in individuals with the metabolic syndrome. In 53 participants with different degrees of adiposity and presence or absence of the metabolic syndrome, analysis of expression of 24 ATM-specific marker genes in SAT and VAT showed the following rank order in both fat depots: lean $<$ overweight $=$ obese $<$ the metabolic syndrome. The lack of difference in gene expression of ATM markers between the overweight and the obese groups may be related to comparable profiles in terms of variables associated with the metabolic syndrome. ATM gene expression in the two fat depots was clearly lower in lean individuals than in all other groups with higher adiposity; it was also higher in obese individuals with the metabolic syndrome than in the other three groups, including the group of equally obese individuals without the metabolic syndrome. mRNA levels of ATM markers in both adipose tissue depots positively correlated with BMI, weight, fat mass, waist, WHR and computed tomography visceral/total fat; they negatively correlated with fat-free mass. A positive correlation was also observed between ATM mRNA levels in the two fat depots and plasma levels of insulin, NEFA, triacylglycerol and diastolic blood pressure. Regarding insulin sensitivity, the analysis revealed a 
Table 2 Clinical variables of four groups of individuals

\begin{tabular}{|c|c|c|c|c|}
\hline Characteristic & Lean $(n=12)$ & Overweight $(n=12)$ & Obese $(n=15)$ & Metabolic syndrome $(n=14)$ \\
\hline Age (years) & $38 \pm 14$ & $42 \pm 9$ & $45 \pm 9$ & $49 \pm 11$ \\
\hline BMI $\left(\mathrm{kg} / \mathrm{m}^{2}\right)$ & $21.3 \pm 2.0$ & $27.8 \pm 1.2^{\mathrm{c}}$ & $37.0 \pm 6.0^{\mathrm{c} f}$ & $34.0 \pm 3.1^{\mathrm{c} \mathrm{f}}$ \\
\hline Weight (kg) & $61.0 \pm 7.6$ & $79.6 \pm 4.4^{\mathrm{c}}$ & $100.6 \pm 15.1^{\mathrm{c} \mathrm{f}}$ & $91.8 \pm 8.4^{\mathrm{c} \mathrm{d}}$ \\
\hline Fat mass $(\%)$ & $25.8 \pm 5.8$ & $34.7 \pm 4.5^{\mathrm{c}}$ & $45.3 \pm 4.6^{\mathrm{cf}}$ & $42.3 \pm 4.9^{\mathrm{c} \mathrm{e}}$ \\
\hline Fat-free mass $(\%)$ & $74.3 \pm 5.8$ & $65.3 \pm 4.5^{\mathrm{b}}$ & $54.7 \pm 4.6^{\mathrm{cf}}$ & $57.8 \pm 4.9^{\mathrm{c} f}$ \\
\hline Waist $(\mathrm{cm})$ & $74.1 \pm 4.9$ & $92.1 \pm 3.5^{\mathrm{c}}$ & $109.2 \pm 11.2^{\mathrm{c} \mathrm{f}}$ & $107.3 \pm 6.1^{\mathrm{c} \mathrm{f}}$ \\
\hline WHR & $0.76 \pm 0.03$ & $0.84 \pm 0.04^{\mathrm{c}}$ & $0.86 \pm 0.05^{\mathrm{c}}$ & $0.92 \pm 0.05^{\mathrm{c} \mathrm{fh}}$ \\
\hline $\mathrm{CT}$ visceral/total fat & $0.19 \pm 0.06$ & $0.25 \pm 0.07$ & $0.21 \pm 0.04$ & $0.27 \pm 0.06^{\mathrm{b}}$ \\
\hline Systolic BP (mmHg) & $109.1 \pm 13.4$ & $118.5 \pm 9.2$ & $121.9 \pm 11.7^{\mathrm{a}}$ & $129.4 \pm 10.5^{\mathrm{c}}$ \\
\hline Diastolic BP (mmHg) & $66.4 \pm 6.8$ & $73.6 \pm 7.7$ & $77.0 \pm 8.3^{\mathrm{b}}$ & $79.0 \pm 6.7^{\mathrm{c}}$ \\
\hline Glucose $(\mathrm{mmol} / \mathrm{l})$ & $4.8 \pm 0.4$ & $4.8 \pm 0.5$ & $5.4 \pm 0.5$ & $6.3 \pm 1.9^{\mathrm{b} \mathrm{e}}$ \\
\hline Insulin (pmol/1) & $30.5 \pm 14.5$ & $53.7 \pm 16.6^{\mathrm{b}}$ & $64.1 \pm 27.9^{\mathrm{c}}$ & $98.1 \pm 38.3^{\text {c e g }}$ \\
\hline NEFA $(\mu \mathrm{mol} / \mathrm{l})$ & $510.8 \pm 201.6$ & $668.6 \pm 246.4$ & $652.1 \pm 218.0$ & $762.8 \pm 260.5$ \\
\hline Glycerol $(\mu \mathrm{mol} / \mathrm{l})$ & $79.1 \pm 29.0$ & $89.2 \pm 33.1$ & $103.9 \pm 36.4$ & $130.2 \pm 43.1^{\mathrm{b} \mathrm{d}}$ \\
\hline Triacylglycerol (mmol/l) & $0.76 \pm 0.18$ & $1.3 \pm 0.8$ & $1.2 \pm 0.3$ & $2.5 \pm 1.5^{\mathrm{cd} \mathrm{g}}$ \\
\hline Total cholesterol (mmol/l) & $4.6 \pm 0.7$ & $5.1 \pm 1.2$ & $4.8 \pm 1.0$ & $4.6 \pm 1.4$ \\
\hline HDL-cholesterol (mmol/1) & $1.6 \pm 0.3$ & $1.4 \pm 0.4$ & $1.4 \pm 0.3$ & $1.2 \pm 0.2$ \\
\hline Glucose disposal rate ${ }^{\mathrm{i}}$ & $7.2 \pm 2.3$ & $6.6 \pm 5.0$ & $3.7 \pm 1.8^{\mathrm{b}}$ & $2.8 \pm 1.2^{\mathrm{cf}}$ \\
\hline Glucose disposal rate $\mathrm{j}^{\mathrm{j}}$ & $9.7 \pm 3.1$ & $10.2 \pm 7.9$ & $6.9 \pm 3.1$ & $4.9 \pm 2.1^{\mathrm{c} \mathrm{e}}$ \\
\hline
\end{tabular}

Values are means $\pm \mathrm{SD}$; participants (total) $n=53$

${ }^{\mathrm{a}} p<0.05,{ }^{\mathrm{b}} p<0.01,{ }^{\mathrm{c}} p<0.001$ compared with lean; ${ }^{\mathrm{d}} p<0.05,{ }^{\mathrm{e}} p<0.01,{ }^{\mathrm{f}} p<0.001$ compared with overweight; ${ }^{\mathrm{g}} p<0.05,{ }^{\mathrm{h}} p<0.01$ compared with obese;

${ }^{\mathrm{i}}$ Corrected for body weight, $\mathrm{mg} \mathrm{kg}{ }^{-1} \mathrm{~min}^{-1} ;{ }^{\mathrm{j}}$ Corrected for fat-free mass, $\mathrm{mg}$ (kg fat-free mass) ${ }^{-1} \mathrm{~min}^{-1}$; CT, computed tomography

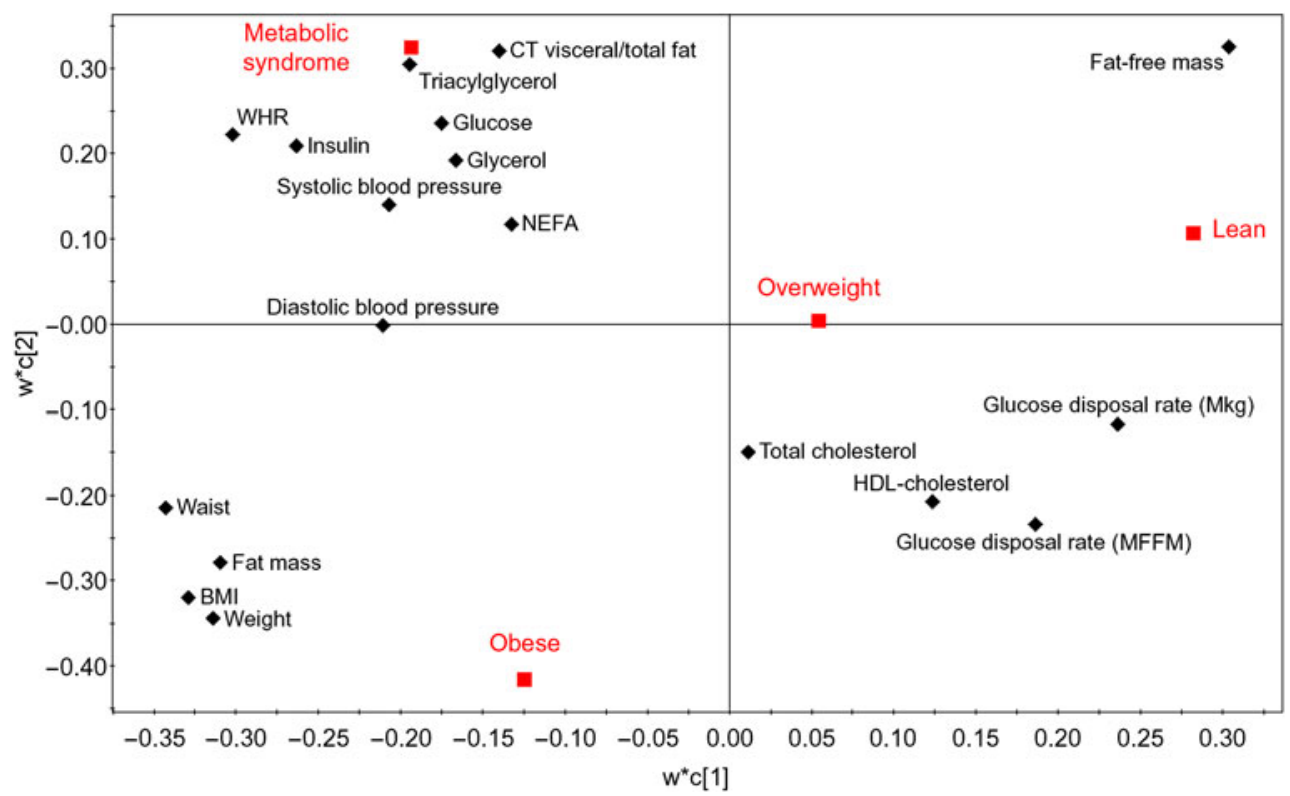

Fig. 2 Partial least square-discriminant analysis of clinical data was used as an exploratory analysis to represent the distribution of four groups of individuals (red font) on the basis of the values of their clinical variables. The $\mathrm{w}^{*} \mathrm{c}$ or loading plot gives a graphical summary of the correlation between clinical parameters (represented by vector $\mathrm{w}^{*}$ ) and groups of individuals (represented by vector c). Axes show $\mathrm{w}^{*} \mathrm{c}$ [component]. $\mathrm{w}^{*} \mathrm{c}[1]$ ( $x$-axis, component 1 , degree of obesity); $\mathrm{w}^{*} \mathrm{c}[2]$ ( $y$-axis, component 2 , presence or not of the metabolic syndrome). The two principal components explained most of the variance of data (by $36 \%$ and $27 \%$, respectively). CT, computed tomography; MFFM, mg (kg fatfree mass) ${ }^{-1} \mathrm{~min}^{-1}$; Mkg, $\mathrm{mg} \mathrm{kg}^{-1} \mathrm{~min}^{-1}$ 


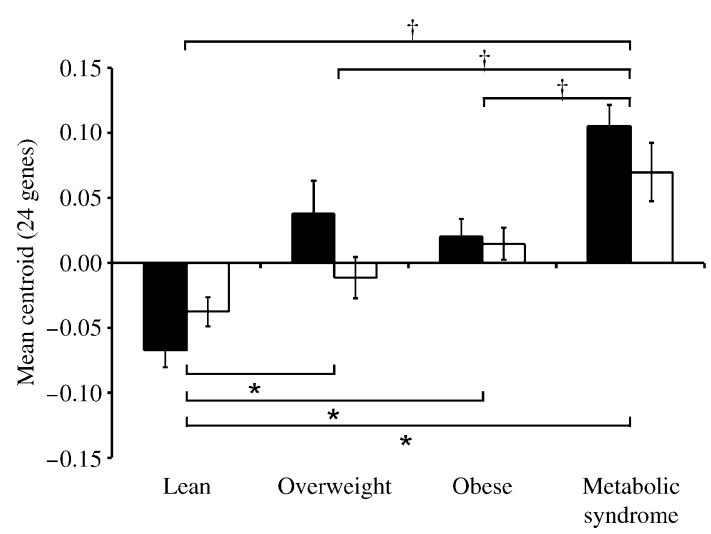

Fig. 3 ATM marker mRNA expression in SAT and VAT in participants as indicated. mRNA levels of 24 markers are expressed as mean centroids \pm SEM in SAT (black bars) and VAT (white bars). ${ }^{*} p<0.05$ for comparison of gene expression in each fat depot between the lean and three other groups of individuals; ${ }^{\dagger} p<0.05$ for as above, but between the metabolic syndrome and three other groups of individuals

negative correlation between ATM mRNA levels in each of the two fat depots and glucose disposal rate.

The limitations of this study include lack of information on macrophage quantity in adipose tissue, abundance of macrophage crown-like structures and adipocyte size. While these data could not be obtained due to the modest amount of adipose tissue material, it would have been interesting to correlate these variables with gene expression data of ATM-specific markers. In fact, it has been shown that an increased proportion of small adipose cells is associated with inflammation in SAT [25]. In addition, because various subpopulations of macrophages may exist and express distinct surface markers depending on the local microenvironment, different ATM markers could be identified in different macrophage subpopulations of adipose tissue. Several macrophage subpopulations have indeed been identified in human adipose tissue [23, 27, 35, 36]. Studies investigating mRNA variations of specific macrophage subpopulations in different adipose tissue locations and/or in different groups of individuals are currently not available due to technical limitations. Further work is therefore warranted.

We used a novel approach to investigate macrophage gene expression pattern in human SAT and VAT in different groups of individuals. First, we characterised and refined a selection of a set of ATM-specific markers by DNA microarray profiling and correlation analyses, confirming these by independent DNA microarray experiments in lean and obese individuals. Considering the plasticity of macrophages, using a spectrum of specific markers for identification of ATM is a more appropriate strategy than use of a single or a few markers [1,21]. Our panel of 24 genes represents the most comprehensive list of human ATMspecific markers reported so far. Although the genes were selected by a 'no a priori hypothesis', it is interesting to note that some of the markers shared related characteristics. CD204 (also known as MSR1), M130, SCARA2 (also known as MARCO) and GP110 (also known as CD68) encode macrophage scavenger receptors with wide roles in host defence and tissue homeostasis [37]. Other ATM marker genes (CDSIGN (also known as CD209), SIGLEC3 (also known as CD33) and CD169 (also known as SIGLEC1)) have been described as macrophage cell
Table 3 Correlations of centroids of macrophage marker gene expression in SAT and VAT with clinical variables of 53 individuals

Values are Pearson's $r$ correlation coefficient

${ }^{\mathrm{a}} p<0.05,{ }^{\mathrm{b}} p \leq 0.01,{ }^{\mathrm{c}} p \leq 0.001$

${ }^{\mathrm{d}}$ Corrected for body weight, $\mathrm{mg} \mathrm{kg}{ }^{-1} \mathrm{~min}^{-1}$

${ }^{\mathrm{e}}$ Corrected for fat-free mass, mg $(\mathrm{kg} \text { fat-free mass })^{-1} \mathrm{~min}^{-1}$

$\mathrm{CT}$, computed tomography

\begin{tabular}{lll}
\hline Variable & SAT mean centroid & VAT mean centroid \\
\hline BMI $\left(\mathrm{kg} / \mathrm{m}^{2}\right)$ & $0.473^{\mathrm{c}}$ & $0.447^{\mathrm{c}}$ \\
Weight $(\mathrm{kg})$ & $0.480^{\mathrm{c}}$ & $0.461^{\mathrm{c}}$ \\
Fat mass $(\%)$ & $0.563^{\mathrm{c}}$ & $0.417^{\mathrm{b}}$ \\
Fat-free mass $(\%)$ & $-0.513^{\mathrm{c}}$ & $-0.419^{\mathrm{b}}$ \\
Waist $(\mathrm{cm})$ & $0.592^{\mathrm{c}}$ & $0.515^{\mathrm{c}}$ \\
WHR & $0.653^{\mathrm{c}}$ & $0.478^{\mathrm{c}}$ \\
CT visceral/total fat & $0.480^{\mathrm{c}}$ & $0.308^{\mathrm{a}}$ \\
Systolic BP $(\mathrm{mmHg})$ & $0.343^{\mathrm{a}}$ & $0.279^{\mathrm{a}}$ \\
Diastolic BP $(\mathrm{mmHg})$ & $0.440^{\mathrm{c}}$ & $0.351^{\mathrm{b}}$ \\
Glucose $(\mathrm{mmol} / \mathrm{l})$ & 0.223 & $0.425^{\mathrm{b}}$ \\
Insulin $(\mathrm{pmol} / \mathrm{l})$ & $0.654^{\mathrm{c}}$ & $0.553^{\mathrm{c}}$ \\
NEFA $(\mu \mathrm{mol} / \mathrm{l})$ & $0.318^{\mathrm{a}}$ & $0.364^{\mathrm{b}}$ \\
Glycerol $(\mu \mathrm{mol} / \mathrm{l})$ & 0.266 & $0.504^{\mathrm{c}}$ \\
Triacylglycerol $(\mathrm{mmol} / \mathrm{l})$ & $0.401^{\mathrm{b}}$ & $0.517^{\mathrm{c}}$ \\
Total cholesterol $(\mathrm{mmol} / \mathrm{l})$ & -0.14 & 0.028 \\
HDL-cholesterol $(\mathrm{mmol} / \mathrm{l})$ & $-0.363^{\mathrm{b}}$ & -0.221 \\
Glucose disposal rate & $-0.631^{\mathrm{c}}$ & $-0.587^{\mathrm{c}}$ \\
Glucose disposal rate & $-0.574^{\mathrm{c}}$ & $-0.539^{\mathrm{c}}$ \\
\hline
\end{tabular}



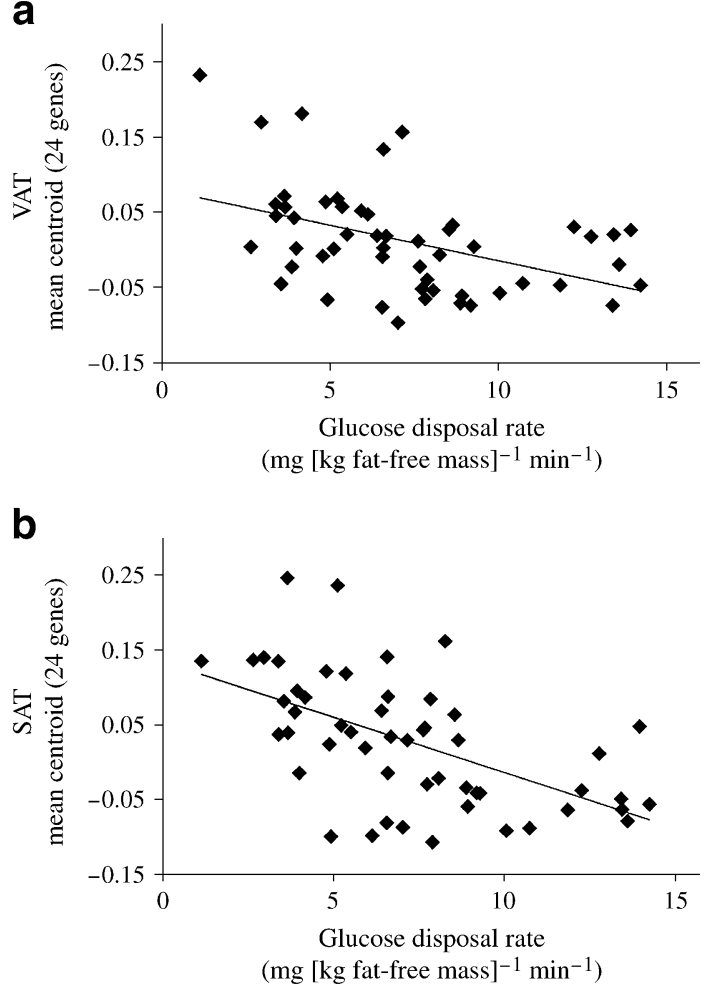

Fig. 4 Correlation analyses of macrophage-specific marker gene expression. Correlation between glucose disposal rate $(\mathrm{mg}$ [kg fatfree mass] ${ }^{-1} \mathrm{~min}^{-1}$ ) and (a) VAT and (b) SAT mean centroid for 24 genes; $n=53$ participants. (a) $r=-0.539, p<0.001$; (b) $r=-0.574$, $p<0.001$. Linear regression lines are shown

adhesion receptors binding carbohydrate ligands. CD14, SLEB10 (also known as IRF5) and UNQ248/PRO285 (also known as TLR7) belong to the Toll-like receptor pathways [38]. Our selection criteria picked up three marker genes (CD20L1 (also known as MS4A4A), CD20L3 (also known as MS4A6A), CD20L4 (also known as MS4A7)) from a cluster of genes expressed in haemapoietic cells [39]. Two genes encoding class II major histocompatibility complex cell surface glycoproteins (HLA-DRA1 (also known as HLA-DRA), HLADM) were represented. Moreover, CD14 and GP110 encode widely used cell-surface markers for identification of human ATM by immunohistochemistry or flow cytometry $[11,27,40,41]$. Other genes of the list, such as HLA-DR, M130, CDSIGN and IL-10 (also known as $I L 10$ ), have been shown to be highly expressed in human ATMs [22, 23]. TRAP is highly expressed in adipose tissue of obese individuals where it is secreted from ATM [42]. Second, we investigated the association between ATMspecific gene expression levels and clinical variables in paired SAT and VAT samples from four thoroughly phenotyped groups of lean, overweight, obese and the metabolic syndrome individuals. Positive associations with obesity have been reported for a limited number of ATM transcripts, such as GP110, M130 and CD206 [12, 24, 26,
41, 43]. Accordingly, we found higher GP110 and M130 mRNA levels in obese than in lean individuals. Unlike previous studies, we used a large panel of 24 ATM-specific markers and showed positive correlation between ATM gene expression and fat mass. Data on ATM gene expression in the context of the metabolic complications of obesity are limited. Expression of five inflammatory genes in SAT was shown to be different between insulinresistant and insulin-sensitive overweight patients [25]. In our study, we found significantly increased mRNA levels of 24 ATM-specific markers in the metabolic syndrome patients compared with all other groups in both fat depots.

An important predictive factor of the metabolic risk is the pattern of adipose tissue distribution. Generally, VAT is considered to be highly associated with the metabolic risk factors [44]. The existence of phenotypic and the metabolic differences between various adipose tissue depots implies differential gene expression profiles. Many studies with various experimental designs have searched for depotspecific differences of inflammatory molecules in humans [12, 13, 15-17, 24, 26, 45]. To date, only M130 and GP110 have been compared between SAT and VAT in different groups of individuals. For M130, our data showing no significant difference between SAT and VAT gene expression are consistent with the results of Shakeri-Manesch et al. for lean and morbidly obese individuals [26] and inconsistent with those of O'Rourke et al., who examined morbidly obese women and reported higher expression in VAT [13]. GP110 has been reported to have an equal interdepot expression in obese and lean individuals [16, 24, 26], which is in line with our findings. One team has reported contradicting results showing higher mRNA levels of GP110 in omental adipose tissue of lean and obese patients [12]. However, these authors recruited women and men, while all our participants were all women. Our study revealed that there was no systematic difference between fat depots for expression of ATM-specific markers. For some genes, the degree of obesity influenced the relative expression in the two depots. Importantly, correlations between ATM gene expression and clinical variables related to obesity and the metabolic

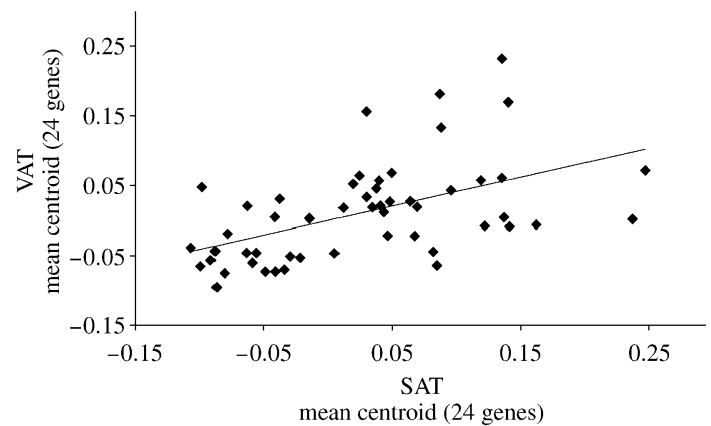

Fig. 5 Correlation between SAT and VAT mean centroids of 24 genes; $r=0.510, p<0.001$. The linear regression line is shown 
Table 4 Comparison of macrophage markers mRNA expression between SAT and VAT depots in lean, overweight, obese and metabolic syndrome individuals
Gene symbols as listed in Entrez

Gene (www.ncbi.nlm.nih.gov/

entrez/query.fcgi?

$\mathrm{CMD}=$ search $\& \mathrm{DB}=$ gene)

VAT or SAT refers to higher mRNA levels in the indicated fat depot based on pair-wise analysis of $2^{\Delta \mathrm{C}_{\mathrm{t}}}$ mRNA values between SAT and VAT

(Wilcoxon's signed rank test)

${ }^{\mathrm{a}} p<0.05,{ }^{\mathrm{b}} p<0.01$

\begin{tabular}{|c|c|c|c|c|}
\hline \multirow[t]{2}{*}{ Gene symbol } & \multicolumn{4}{|c|}{ Adipose tissue type per body weight group } \\
\hline & Lean $(n=12)$ & Overweight $(n=12)$ & Obese $(n=15)$ & Metabolic syndrome $(n=14)$ \\
\hline$A C P 5$ & VAT $^{a}$ & $\mathrm{SAT}^{\mathrm{a}}$ & $\mathrm{SAT}^{\mathrm{b}}$ & $\mathrm{SAT}^{\mathrm{b}}$ \\
\hline CD14 & NS & NS & NS & NS \\
\hline CD163 & NS & NS & NS & NS \\
\hline CD209 & NS & SAT $^{\mathrm{a}}$ & NS & NS \\
\hline$C D 33$ & NS & SAT $^{\mathrm{a}}$ & NS & $\mathrm{SAT}^{\mathrm{a}}$ \\
\hline CD68 & NS & $\mathrm{SAT}^{\mathrm{a}}$ & NS & $\mathrm{SAT}^{\mathrm{a}}$ \\
\hline$A D A P 2$ & $\mathrm{VAT}^{\mathrm{b}}$ & NS & NS & NS \\
\hline CLEC10A & NS & NS & NS & NS \\
\hline$F C G R 2 B$ & NS & $\mathrm{SAT}^{\mathrm{b}}$ & NS & $\mathrm{SAT}^{\mathrm{a}}$ \\
\hline$F C N 1$ & NS & NS & NS & NS \\
\hline$H L A-D M A$ & NS & NS & NS & NS \\
\hline$H L A-D R A$ & NS & $\mathrm{SAT}^{\mathrm{b}}$ & $\mathrm{SAT}^{\mathrm{b}}$ & $\mathrm{SAT}^{\mathrm{b}}$ \\
\hline IL10 & VAT $^{a}$ & NS & NS & $\mathrm{SAT}^{\mathrm{a}}$ \\
\hline IRF5 & NS & SAT $^{\mathrm{a}}$ & NS & $\mathrm{SAT}^{\mathrm{a}}$ \\
\hline$K Y N U$ & $\mathrm{VAT}^{\mathrm{b}}$ & NS & NS & NS \\
\hline LIPA & NS & $\mathrm{SAT}^{\mathrm{a}}$ & $\mathrm{SAT}^{\mathrm{a}}$ & $\mathrm{SAT}^{\mathrm{b}}$ \\
\hline MARCO & VAT $^{a}$ & NS & NS & NS \\
\hline$M S 4 A 4 A$ & $\mathrm{VAT}^{\mathrm{a}}$ & NS & NS & NS \\
\hline$M S 4 A 6 A$ & NS & SAT $^{\mathrm{a}}$ & NS & NS \\
\hline$M S 4 A 7$ & VAT $^{a}$ & NS & NS & NS \\
\hline MSRI & NS & $\mathrm{SAT}^{\mathrm{b}}$ & $\mathrm{SAT}^{\mathrm{b}}$ & $\mathrm{SAT}^{\mathrm{b}}$ \\
\hline SIGLECI & $\mathrm{VAT}^{\mathrm{a}}$ & NS & NS & NS \\
\hline$S L C O 2 B 1$ & $\mathrm{VAT}^{\mathrm{b}}$ & NS & VAT $^{a}$ & NS \\
\hline TLR7 & VAT $^{a}$ & NS & NS & NS \\
\hline
\end{tabular}

syndrome were as strong in SAT as in VAT. Hence, we found no evidence that the deleterious effect of VAT accumulation on the metabolic syndrome variables is related to higher expression of ATM markers in VAT.

Although this study was not designed to investigate the phenotypes of ATMs, comparison of the 24 ATM-specific markers with known human M1 and M2 macrophage markers revealed that six genes (CD204, CDSIGN, CD301, CD20L1, CD20L3 and CESD (also known as $L I P A)$ ) are typical of human blood monocyte-derived macrophages polarised in vitro toward the M2 phenotype [20]. Other genes from our panel that could be assigned to M2 macrophages are $I L-10$ and possibly M130. The haemoglobin scavenger receptor gene $M 130$ has been suggested to be rather M2-like [23], but has also been reported to be regulated by pro- and anti-inflammatory stimuli [46]. None of the 24 ATM markers were classified as M1. Importantly, it should be recognised that the current classification is imprecise and that there is a need for it to be expanded to encompass a spectrum of macrophage populations with different shades of activation [21]. However, according to the current nomenclature, our data are in agreement with a remodelling phenotype for human
ATM expressing pro- and anti-inflammatory markers [22, 47]. These M2-like genes showed increased expression in SAT and VAT in the metabolic syndrome compared with lean individuals and were correlated with variables of adiposity and the metabolic syndrome. Therefore, we could not demonstrate a switch from M2 to M1 phenotype as reported in mice developing obesity [48, 49]. This is best exemplified by variations in the mRNA levels of the antiinflammatory cytokine $I L-10$, which are higher in lean than in obese mouse ATM, but lower in lean than in obese and the metabolic syndrome SAT and VAT in humans [48]. As the link in mice of M1-activated ATM and adipose tissue inflammation to obesity and insulin resistance is not supported by data in humans, further work is now needed to determine the role of human ATM with remodelling phenotype in the development of the metabolic syndrome.

In conclusion, our data show that expression of ATM markers is increased with obesity, insulin resistance and occurrence of the metabolic syndrome in human SAT as well as in VAT. This suggests that the worsening of the metabolic status in obese individuals cannot be simply ascribed to ATM-mediated inflammation of visceral fat. Identification of specific ATM populations in different fat 
depots in individuals with different the metabolic abnormalities is warranted to identify potiential pharmacological treatments of obesity and linked disturbances by targeted modulation of macrophage phenotype.

Acknowledgements This work was supported by grant IGA NS 10519-3-2009 and IGA NR 8066-3/2004 of the Czech Ministry of Health, by Project MSM 0021620814 of the Ministry of Education of the Czech Republic, by Inserm, by Région Midi-Pyrénées and by Integrated Project HEPADIP (www.hepadip.org) Contract LSHM-CT-2005018734, Integrated Project MOLPAGE (www.molpage.org) Contract LSH-2003-1.1.3-1 and Collaborative Project ADAPT (www.adapt-eu. net) Contract HEALTH-F2-2008-2011 00. We are indebted to Z. Parizkova, C. Valle and M.-A. Marques for technical expertise.

Duality of interest The authors declare that there is no duality of interest associated with this manuscript.

\section{References}

1. Cefalu WT (2009) Inflammation, insulin resistance, and type 2 diabetes: back to the future? Diabetes 58:307-308

2. Shoelson SE, Goldfine AB (2009) Getting away from glucose: fanning the flames of obesity-induced inflammation. Nat Med $15: 373-374$

3. Bays HE, Gonzalez-Campoy JM, Bray GA et al (2008) Pathogenic potential of adipose tissue and metabolic consequences of adipocyte hypertrophy and increased visceral adiposity. Expert Rev Cardiovasc Ther 6:343-368

4. Despres JP, Lemieux I, Bergeron J et al (2008) Abdominal obesity and the metabolic syndrome: contribution to global cardiometabolic risk. Arterioscler Thromb Vasc Biol 28:1039-1049

5. Iannucci CV, Capoccia D, Calabria M, Leonetti F (2007) Metabolic syndrome and adipose tissue: new clinical aspects and therapeutic targets. Curr Pharm Des 13:2148-2168

6. Vague J (1947) La differénciation sexuelle, facteur determinant des formes de l'obésité. Presse Méd 55:339-340

7. Fox CS, Massaro JM, Hoffmann U et al (2007) Abdominal visceral and subcutaneous adipose tissue compartments: association with metabolic risk factors in the Framingham Heart Study. Circulation 116:39-48

8. Goodpaster BH, Krishnaswami S, Harris TB et al (2005) Obesity, regional body fat distribution, and the metabolic syndrome in older men and women. Arch Intern Med 165:777-783

9. Pascot A, Lemieux S, Lemieux I et al (1999) Age-related increase in visceral adipose tissue and body fat and the metabolic risk profile of premenopausal women. Diabetes Care 22:1471-1478

10. Pou KM, Massaro JM, Hoffmann U et al (2009) Patterns of abdominal fat distribution: the Framingham Heart Study. Diabetes Care 32:481-485

11. Cancello R, Henegar C, Viguerie N et al (2005) Reduction of macrophage infiltration and chemoattractant gene expression changes in white adipose tissue of morbidly obese subjects after surgery-induced weight loss. Diabetes 54:2277-2286

12. Harman-Boehm I, Bluher M, Redel H et al (2007) Macrophage infiltration into omental vs subcutaneous fat across different populations: effect of regional adiposity and the comorbidities of obesity. J Clin Endocrinol Metab 92:2240-2247

13. O'Rourke RW, Metcalf MD, White AE et al (2009) Depot-specific differences in inflammatory mediators and a role for NK cells and IFN-gamma in inflammation in human adipose tissue. Int $\mathrm{J}$ Obes (Lond) 33:978-990
14. Cinti S, Mitchell G, Barbatelli G et al (2005) Adipocyte death defines macrophage localization and function in adipose tissue of obese mice and humans. J Lipid Res 46:2347-2355

15. Gomez-Ambrosi J, Catalan V, Diez-Caballero A et al (2004) Gene expression profile of omental adipose tissue in human obesity. FASEB J 18:215-217

16. Liu A, McLaughlin T, Liu T et al (2009) Differential intraabdominal adipose tissue profiling in obese, insulin-resistant women. Obes Surg 19:1564-1573

17. Vohl MC, Sladek R, Robitaille J et al (2004) A survey of genes differentially expressed in subcutaneous and visceral adipose tissue in men. Obes Res 12:1217-1222

18. Spalding KL, Arner E, Westermark PO et al (2008) Dynamics of fat cell turnover in humans. Nature 453:783-787

19. Duffaut C, Zakaroff-Girard A, Bourlier V et al (2009) Interplay between human adipocytes and T lymphocytes in obesity: CCL20 as an adipochemokine and $\mathrm{T}$ lymphocytes as lipogenic modulators. Arterioscler Thromb Vasc Biol 29:1608-1614

20. Martinez FO, Gordon S, Locati M, Mantovani A (2006) Transcriptional profiling of the human monocyte-to-macrophage differentiation and polarization: new molecules and patterns of gene expression. J Immunol 177:7303-7311

21. Mosser DM, Edwards JP (2008) Exploring the full spectrum of macrophage activation. Nat Rev Immunol 8:958-969

22. Bourlier V, Zakaroff-Girard A, Miranville A et al (2008) Remodeling phenotype of human subcutaneous adipose tissue macrophages. Circulation 117:806-815

23. Zeyda M, Farmer D, Todoric J et al (2007) Human adipose tissue macrophages are of an anti-inflammatory phenotype but capable of excessive pro-inflammatory mediator production. Int $\mathrm{J}$ Obes (Lond) 31:1420-1428

24. Huber J, Kiefer FW, Zeyda M et al (2008) CC chemokine and CC chemokine receptor profiles in visceral and subcutaneous adipose tissue are altered in human obesity. J Clin Endocrinol Metab 93:3215-3221

25. McLaughlin T, Deng A, Gonzales O et al (2008) Insulin resistance is associated with a modest increase in inflammation in subcutaneous adipose tissue of moderately obese women. Diabetologia 51:2303-2308

26. Shakeri-Manesch S, Zeyda M, Huber J, Ludvik B, Prager G, Stulnig TM (2009) Diminished upregulation of visceral adipose heme oxygenase-1 correlates with waist-to-hip ratio and insulin resistance. Int J Obes (Lond) 33:1257-1264

27. Curat CA, Miranville A, Sengenes C et al (2004) From blood monocytes to adipose tissue-resident macrophages: induction of diapedesis by human mature adipocytes. Diabetes 53:12851292

28. Miranville A, Heeschen C, Sengenes C, Curat CA, Busse R, Bouloumie A (2004) Improvement of postnatal neovascularization by human adipose tissue-derived stem cells. Circulation 110:349355

29. Alberti KG, Zimmet P, Shaw J (2005) The metabolic syndromea new worldwide definition. Lancet 366:1059-1062

30. Fujioka S, Matsuzawa Y, Tokunaga K, Tarui S (1987) Contribution of intra-abdominal fat accumulation to the impairment of glucose and lipid metabolism in human obesity. Metabolism 36:54-59

31. DeFronzo RA, Tobin JD, Andres R (1979) Glucose clamp technique: a method for quantifying insulin secretion and resistance. Am J Physiol 237:E214-E223

32. Capel F, Klimcakova E, Viguerie N et al (2009) Macrophages and adipocytes in human obesity: adipose tissue gene expression and insulin sensitivity during calorie restriction and weight stabilization. Diabetes 58:1558-1567

33. Perez-Enciso M, Tenenhaus M (2003) Prediction of clinical outcome with microarray data: a partial least squares discriminant analysis (PLS-DA) approach. Hum Genet 112:581-592 
34. Mootha VK, Lindgren CM, Eriksson KF et al (2003) PGC1alpha-responsive genes involved in oxidative phosphorylation are coordinately downregulated in human diabetes. Nat Genet $34: 267-273$

35. Kovacikova M, Sengenes C, Kovacova Z et al (2010) Dietary intervention-induced weight loss decreases macrophage content in adipose tissue of obese women. Int J Obes (Lond). doi:10.1038/ ijo. 2010.112

36. Wentworth JM, Naselli G, Brown WA et al (2010) Proinflammatory $\mathrm{CD} 11 \mathrm{c}+\mathrm{CD} 206+$ adipose tissue macrophages are associated with insulin resistance in human obesity. Diabetes 59:1648-1656

37. Greaves DR, Gordon S (2009) The macrophage scavenger receptor at 30 years of age: current knowledge and future challenges. J Lipid Res 50(Suppl):S282-S286

38. Kawai T, Akira S (2010) The role of pattern-recognition receptors in innate immunity: update on Toll-like receptors. Nat Immunol 11:373-384

39. Zuccolo J, Bau J, Childs SJ, Goss GG, Sensen CW, Deans JP (2010) Phylogenetic analysis of the MS4A and TMEM176 gene families. PLoS One 5:e9369

40. Clement K, Viguerie N, Poitou C et al (2004) Weight loss regulates inflammation-related genes in white adipose tissue of obese subjects. FASEB J 18:1657-1669

41. Martinez O, de Victoria E, Xu X, Koska J et al (2009) Macrophage content in subcutaneous adipose tissue: associations with adiposity, age, inflammatory markers, and whole-body insulin action in healthy Pima Indians. Diabetes 58:385-393
42. Lang P, van Harmelen V, Ryden M et al (2008) Monomeric tartrate resistant acid phosphatase induces insulin sensitive obesity. PLoS One 3:e1713

43. Weisberg SP, McCann D, Desai M, Rosenbaum M, Leibel RL, Ferrante AW Jr (2003) Obesity is associated with macrophage accumulation in adipose tissue. J Clin Invest 112:1796-1808

44. Tarantino G, Colicchio P, Conca P et al (2009) Young adult obese subjects with and without insulin resistance: what is the role of chronic inflammation and how to weigh it non-invasively? J Inflamm (Lond) 6:6

45. Cancello R, Tordjman J, Poitou C et al (2006) Increased infiltration of macrophages in omental adipose tissue is associated with marked hepatic lesions in morbid human obesity. Diabetes 55:1554-1561

46. Buechler C, Ritter M, Orso E, Langmann T, Klucken J, Schmitz G (2000) Regulation of scavenger receptor CD163 expression in human monocytes and macrophages by pro- and antiinflammatory stimuli. J Leukoc Biol 67:97-103

47. Bourlier V, Bouloumie A (2009) Role of macrophage tissue infiltration in obesity and insulin resistance. Diabetes Metab $35: 251-260$

48. Lumeng CN, Bodzin JL, Saltiel AR (2007) Obesity induces a phenotypic switch in adipose tissue macrophage polarization. J Clin Invest 117:175-184

49. Lumeng CN, DelProposto JB, Westcott DJ, Saltiel AR (2008) Phenotypic switching of adipose tissue macrophages with obesity is generated by spatiotemporal differences in macrophage subtypes. Diabetes 57:3239-3246 